\title{
THE ROLE OF SELF-KNOWLEDGE IN ARISTOTELIAN FRIENDSHIP
}

Héctor Zagal Arreguin* hzagal@up.edu.mx

\begin{abstract}
This paper discusses the capital role that friendship plays in moral self-knowledge within Aristotelian Ethics. It focuses on the different ways in which a friend may shed light on the understanding of our behavior. Great attention is paid to the accounts of certain commentators (especially, of Richard Kraut and Anthony Kenny) on this subject. The paper tries to provide a conciliatory interpretation between views on self-knowledge that are, only in appearance, irreconcilable.
\end{abstract}

Keywords Aristotelian self-knowledge, Friendship, Virtue, Selfconsciousness

RESUMO Este artigo discute o papel fundamental desempenhado pela amizade no processo de autoconhecimento moral dentro da Ética aristotélica. Ele se concentra nas diferentes vias pelas quais um amigo pode esclarecer o processo de compreensão do nosso comportamento. Dedicamos grande atenção às abordagens de alguns comentadores acerca deste tema, especialmente a de Richard Kraut e Anthony Kenny. O artigo procura propor uma interpretação conciliadora entre abordagens sobre o autoconhecimento que são, apenas aparentemente, incompativeis.

Palavras-Chave Autoconhecimento aristotélico, Amizade, Virtude, Autoconsciência

* PhD em Filosofia pela Universidad Panamericana. Artigo recebido em 29/04/2009 e aprovado em 1 o/10/2009.

KRITERION, Belo Horizonte, no 121, Jun./2010, p. 117-128. 


\section{The importance of knowledge in human life}

One of the most controversial claims of Aristotelian Ethics is that "we can contemplate (theorein) our neighbors (tous pelas) better than ourselves and their actions (praxeis) better than our own". ${ }^{1}$ To be sure, it is a highly relevant statement that mirrors the importance that Aristotle grants friendship within human life. It is not a matter of chance, therefore, that the philosopher makes such an emphasis on the need of having friends. ${ }^{2}$ These, among many other things, help man to know himself. Self-knowledge, according to Aristotle, is not an accidental feature of the virtuous life but a fundamental part of it. The only way in which we can be adequately conscious of our moral virtues and flaws is to rely on friends who make us aware of the nature of our own conduct and condition. Such an apparently radical position can only be understood once the assumptions it entails are clarified.

In the first place, it is clear that underneath all the Aristotelian discussion on self-knowledge lies a wider and broader analysis on the role of knowledge in human life. The importance of knowledge and self-knowledge is underlined in the Nicomachean Ethics by an argumentation that has aroused many interpretations among scholars and that has been reconstructed with a great number of variants. $^{3}$ I refer in particular to a passage in which Aristotle speaks of the consciousness we have of our own existence and virtues. I quote extensively the passage due to its importance for our discussion:

But if life itself is good and pleasant, (agathon kai edu) which it seems to be, from
the very fact that all men desire (oregesthai) it, and particularly those who are good
and blessed (epieikes kai makarious); for to such men life is most desirable, and
their existence is the most blessed; and if he who sees perceives (aisthanetai) that
he sees, and he who hears that he hears, and he who walks that he walks, and in the
case of all other activities similarly there is something which perceives that we are
active, so that if we perceive, we perceive that we perceive (kan aisthanometh'oti
aisthanometha), and if we think, that we think (kan nomen oti noumen); and if to
perceive that we perceive or think is to perceive that we exist (for existence is defined

1 Nicomachean Ethics, 1169b33. For the quotations of Aristotle I will use Jonathan Barnes (Ed.). The Complete Works of Aristotle, New Jersey: Princeton University Press, 1991.

2 Despite this intention of Aristotle, some scholars have neglected the specific weight of friendship within a fulfilled existence. An example of this is Sarah Broadie's Ethics with Aristotle, Oxford: Oxford University Press, 1993. Although it is a remarkable book in many senses, the fact that it lacks a chapter on this virtue shows us that the importance of friendship is sometimes not easily recognized.

3 Perhaps the most elaborate analysis in this regard is the footnote of David Ross in his translation of this passage of the Nicomachean Ethics. Cfr. David Ross, The Works of Aristotle Translated into English, Oxford: Clarendon Press, 1915. The analysis of Cooper and Kenny are quite interesting as well, but as it will later be seen, my conclusions lead in a somewhat different direction. John M. Cooper, "Aristotle on Friendship", Essays on Aristotle's Ethics, California, University of California Press, 1980, p. 311ss; Anthony Kenny, Aristotle on the Perfect Life, Oxford, Clarendon Press, 1997, p. 44ss. 
as perceiving or thinking) (to gar einai en aisthanesthai e noein); and if perceiving that one lives is one of the things that are pleasant in themselves (for life is by nature good, and to perceive what is good present in oneself is pleasant) (fusei gar agathon zoe to de agathon uparxon en eauto aisthenesthai edu); and if life is desirable, and particularly so for good men, because to them existence is good and pleasant (for they are pleased at the consciousness of what is in itself good) (sun-aisthenomenoi gar tou kath auto agathou edontai); and if virtuous man is to know himself, he is to his friend also (for his friend is another self) (heteros gar autos o filos estin): then as his own existence is desirable because he perceived his own goodness (aireton), and such perception is pleasant in itself (to aisthanesthai autou agathou). He needs, therefore, to be conscious of the existence of his friend as well (sunaisthenesthai ara dei kai tou filou oti estin), and this will be realized in their living together and sharing in discussion and thought (logon kai dianoias); for this is what living together would seem to mean in the case of man, and not, as in the case of cattle, feeding in the same place.

Far from proposing a definitive reading of the passage, I would like to high-lighten some of its most fundamental aspects in order to shed light on the Aristotelian theses on self-knowledge:

1. Life itselfis good and is even more pleasant when we have consciousness of it.

2. To be aware of one's existence when one is good and virtuous is even more pleasant.

3. If we are disposed towards our friends in the same way we are disposed towards ourselves (that is to say, if our friend is 'another self"), the existence and the virtues of others will also please us.

4. We can take great pleasure in the existence of a friend when we interact with him in the properly human fashion, i.e., when we communicate to him our words and thoughts.

Aristotle emphasizes thereby the inherent wish of man to know reality and the pleasure that goes in hand with that knowledge. ${ }^{4}$ In a certain way, the activity itself of knowing 'something' is an essential part of human life, but to be aware of our own knowledge is even more fundamental. Self-consciousness allows us to appreciate the endeavors one has had to go through in order to achieve a specific end and, more importantly, the real value of the things we know, among of which it occupies a noteworthy position the knowledge we have of ourselves and of our capacities. It becomes clear, consequently, that there is a hierarchy among the objects susceptible to be known by us. Among the many realities towards which the human mind can direct itself, one of which we enjoy the most is acknowledging ourselves as virtuous and 
competent moral agents. One cannot compare, for instance, the consciousness of our abilities as ping-pong players with the consciousness of our ethical virtues.

Considerations of our ethical virtues go in hand with the memory of the particular activities in which we have developed and perfected our skills. Awareness of how we have practiced virtue is an essential element of happiness, for we take pleasure in having oriented our will adequately to an end, as well as in having deliberated correctly upon the necessary means to achieve it. This means, to put it briefly, that we cannot achieve happiness without self-knowledge. Otherwise, we could not even be aware either of the favorable state we live in or of the hard work we have done to reach it. Although it may seem quite paradoxical, to be aware of our efforts to reach happiness is an important part of happiness itself. ${ }^{5}$

This argumentation in the above quoted passage seems to take an important turn when Aristotle mentions the pleasure we take in being aware of the existence of our friends. At first glance, perhaps, it does not seem clear what is at the basis of such phenomenon. Aristotle does not explicitly mention this here, but such pleasure seems to be closely linked with virtuous friendship. The bond between two individuals by means of virtue builds up, according to Aristotle, the most authentic kind of friendship; it is not grounded on such contingent interests as friendships based on pleasure or utility. ${ }^{6}$ Among virtuous individuals exists a fundamental agreement on the goods one wants for oneself and for the others. Furthermore, within virtuous friendship one thinks that the triumphs and personal success of a friend also belong to oneself. When one considers the goals towards which his friend aspires are virtuous and one helps him to reach them, one judges rightly that the wellbeing of that friend has been produced in some kind of co-authorship with oneself. As Sherman remarks, these shared successes are very common within family life. ${ }^{7}$ A mother feels, for example, that she has had a decisive participation

5 The claim in book I about the performance of virtuous acts throughout life (1098a18-20) makes emphasis on this constancy of purpose one must have in the exercise of our superior faculties and, consequently, of virtue. Happiness is only such if we evaluate it in the complete horizon of a life. It is becomes very important, thus, that we pay serious attention to our moral merits and flaws.

6 Nichomachean Ethics, 1157b25-35.

7 In this regard the analysis of Sherman is quite interesting: "There is a related way in which we experience a friend's happiness or sorrow as our own. Accomplishments and failures which are not explicitly our own are none the less, through an extension of self, sources of pride and shame. So Aristotle says in $R h$. II. 6: 'And individuals feel shame whenever they have acts or deeds credited to them which bring some disrespect, whether the acts be their own, or those of their ancestors, or those of other persons to whom they bear some close relation' (1385a1-3). Thus, when our children do well, we feel pride in their achievements, and when they do poorly, shame, as if we ourselves had fallen short. It is not that we are responsible for their errors (though as parents we may be), but that through the sense of belonging 
in the distinct progresses made by his son. In virtuous friendships, however, consciousness of the fulfilled goals reaches new dimensions, given that in these cases there is a mutual determination built upon the similar rational capacities of both agents. Virtuous friendship, as Aristotle points out insistently, involves a component of election on account of both friends, which is intertwined with the conception of an organized and structured set of goods for a fulfilled existence. In other words, when a virtuous individual chooses to carry out an action, he does not do this with the aim of achieving a 'part' of the fulfilled life but it as a whole. ${ }^{8}$ His deeds ought to conform by themselves a good life within a shared ethical horizon.

This seems to explain why Aristotle uses the above mentioned metaphor of the friend as 'another self'. Here, in contrast with other commentators who seem to read this passage in a rigid and literal way, I advance a more weak and flexible interpretation of this metaphor. ${ }^{9}$ Aristotle does not suggest by any means the complete identification of characters, skills and virtues of two individuals. Even if the philosopher does not demonstrate categorically the opposite, it is not because he lacks the necessary arguments for it, but because it is absurd to suppose that two human beings will have identical reactions in every circumstance, and even more absurd is to assume that they will consciously plan to do always so. If one does not pretend to exert violence upon the Aristotelian theory of friendship, one must affirm that this 'other-self' shares the same orientation towards good within a virtuous life, something that does not imply - as it will later become more evident - that he performs

and attachment we identify with their good. Aristotle thus seems to be suggesting that feelings of shame need not be traced back to actions for which one is oneself responsible: so, for example, I may feel shame for the criminal actions of my sister just in virtue of our relationship, and not because I bear responsibility for her actions or attribute her failings to character traits I share. Whether such feelings of shame are in fact warranted may be a controversial matter, and not one that Aristotle explores carefully" (Nancy Sherman, The Fabric of Character, Aristotel's Theory of Virtue, Clarendon Press, Oxford, 1989, p. 136).

8 "Now it is thought to be a mark of a man of practical wisdom to be able to deliberate well about what is good and expedient for himself, not in some particular respect, e.g. about what sorts of things conduce to health or to strength, but abouth what sorts of thing conduce to the good life in general (oste kai olos an ein fronimos o bouletikos)" (Nicomachean Ethics, 1140a26-28).

9 One rigid interpretation of this passage is that of Hardie: "If it is obvious that there is a sense in which we can be aware of the activities, including the thoughts, of others more easily than we can be aware of our own, it is no less obvious that there is a sense in which our own activities and thoughts are the only activities and thoughts of which we can be aware at all. In the elaboration of his argument in the rest of the chapter Aristotle ignores the difference between a man's awareness of his own thoughts and his awareness of the thoughts of his friend. He does not consider the obvious comment that, unless there were a difference, the thoughts of his friends would have to be literally his own thoughts. The weak link in the argument of the chapter lies in the claim that a friend is an alter ego in the sense that we can be aware of his thoughts as we can be aware of our own" (W. F. R. Hardie, Aristotle's Ethical Theory, Clarendon Press, Oxford, 1980, p. 322-323). 
his actions exactly in the same way as one does. An individual enjoys the existence of the others and his own because he is capable of recognizing the good linked to virtuous actions, regardless if these are his own or not. In the case of virtuous actions by friends, one is capable of recognizing moral feats by means of daily interaction and dialogue in which opinions are expressed. ${ }^{10}$

\section{Learning to be virtuous: the friend as a "mirror"}

Once we have reached this point, it becomes manifest why the existence of friends is pleasant. It is still not quite clear why we contemplate better the actions of our friends than ours. It also remains the question of why this knowledge is essential to us. The above mentioned arguments, however, proportionate enough material to initially approach both questions. Firstly, it seems that we are more capable of evaluating the actions of our friends and his moods because the friend is for us 'another self' that shares our orientation towards good, virtue, and happiness. We possess certain objectivity in regard of his conduct because we know which are his most fundamental aspirations, goals, and wishes. Such things constitute the axis upon which the interchange of thoughts characteristic of virtuous friendships takes place. Secondly, it is clear that passions cloud the knowledge we have ourselves. One of the most representative cases Aristotle mentions is that of young men at the beginning of the Nicomachean Ethics. While examining who are susceptible of living a fulfilled existence within the polis, Aristotle rules out young men due to their excessive passions. ${ }^{11}$ Very often these passions hinder young men to guide their conduct in accordance to reason. In a more mature age, however, passions do not disappear, and for that reason it is necessary to develop virtues such as moderation and self-control to guide appetites in the most convenient manner. It does not follow from this that we can establish a completely effective method to control passions. Even if one is really virtuous the possibility of being

10 As I have already mentioned in the reconstruction of 1170a25-1170b12, verbal exchange is of utmost importance, but as the last lines of that passage illustrate, such interaction essentially defines human interaction. Although this is not the proper place to pursuit that line of argument, it seems to me that this dialogical capacity of man is one of the most firm links between ethics and politics in Aristotle's philosophy. To this respect, the following lines of the Politics are of capital relevance: "The power of speech is intended to set forth the expedient and the inexpedient, and therefore likewise the just and the unjust (dikaiou kai adikou). And it is a characteristic of man that he alone has any sense (aisthesin) of good and evil (agathou and kakoi), of just and unjust, and the like, and the association of living beings who have this sense makes a family and a state (oikian kai poli)" (Politics, 1253a11-12).

11 "[...] since he tends to follow his passions (pathesin aklouthetikos on pataios akousetai), his studies will be vain and unprofitable, because the end (telos) aimed at is not knowledge but action (gnosis alla praxis)" (Nicomachean Ethics, 1098a19). 
blinded by them in certain circumstances of life remains open. Moreover, not only passions but also our affective states can hinder us from appreciating in all its dimensions the situation in which we are and the course of actions that we ought to follow. For example, when a friend accomplishes a great goal, he can easily embrace an excess of confidence and lose perspective of the future, ignoring thereby certain perils or risks he has not yet overcome. Precisely in those cases a virtuous friend seems to have a superior perspective of our state than that rendered to us by means of mere introspection. The knowledge he has of our character and capacities, as well as his own condition as a virtuous moral agent, entitles him to play a very significant role, i.e. to let us enjoy virtuously our moment of glory, reminding us at the same time that we cannot sing our praises too early.

Here as before, it is of extreme importance the idea of shared good among friends, because in the Aristotelian theory it does not seem that one helps friends in such cases because one has an obligation towards them. Instead, one does that due to the pleasure one takes in the friend's existence and virtues. One does not want that his friend commits evil actions because he knows that they will lead his friend away from the shared ethical choices and dispositions that make him a morally favorable and delightful companion. Thus it can be affirmed that a friend is a mirror in which we see reflected an image of ourselves. ${ }^{12}$ When this image is distorted we try to fix it in virtue of the ethical bond one has with that person. The pleasure derived from the happiness of a friend is accompanied by a feeling of sympathy or empathy, which according to Aristotle becomes gradually consolidated as our friendship becomes more close and intimate. We become better mirrors of our friends insofar as we identify ourselves more truly with their joys and sorrows. ${ }^{13}$

Another way in which friends play a role in self-knowledge is when we reflect about their actions and we notice the nature of their virtues. As Sherman has pointed out lucidly, we are not entirely conscious of our own moral merits in several moments of life, and for this reason we need to compare reflexively ourselves with our friends in order to become aware of our own moral feats. ${ }^{14}$ Certain patterns of conduct can be so familiar to us that we do not reflect

12 Magna moralia, 1213a22-24.

13 "It is found difficult, too, to rejoice and to grieve in an intimate way with many people, for it may likely happen that one has at once to be merry with one friend and to mourn with another" (Nicomachean Ethics, 1171a6). The reason of why the philosopher remarks this lies in our incapacity to treat a great number of friends and, specially, of making authentic bonds with people with which we cannot share our thoughts and emotions. The intimacy of dialogue makes us cultivate, according to Aristotle, a series of natural feelings for the wellbeing and prosperity of our friends.

14 Cfr. Nancy Sherman, Op. cit., p. 143. 
about them any more due to their proximity. The bond between friends is here, again, of utmost importance. When we are about to carry out an action we may remember resolutions of our friends in similar instances. The interest we have in our friends makes us gain consciousness of their way of acting. It should not surprise us, therefore, that we associate virtues like magnificence more with our friends than with ourselves. The reason of this is simple: the effects of the friend's actions have fallen upon us. ${ }^{15}$ The practice of virtues of this kind is directed to the people that surround us, but more in particular, to our friends. For that reason, when a virtuous individual looks for a model to direct his conduct, he 'emulates' the dispositions he has contemplated in the people who surround him, and which in some cases have benefited him in a substantive manner. This imaginative exercise is of great relevance to self-knowledge, for one can make use of his capacities by taking his friends as a model of contrast. Besides, this contrast allows us to realize our particular lacks. By the mere fact of knowing that a friend advantages us in the practice of certain virtues we become more sensible towards our limitations, and in virtue of this acknowledgment we are more capable of overcoming our boundaries.

\section{Excess or lack of contemplative life? An intermediate position}

There is, however, another instance that seems to be even more decisive than the former ones. I refer to the problematic relation between political life and contemplation in Aristotle. Indeed, one of the reasons it seems to be that friends are completely essential to the good life described by the philosopher is that we have to trust them as judges of our deeds, for when we perform virtuous actions we stop considering certain fundamental aspects of our conduct. While commenting this passage of the Nicomachean Ethics, Kraut has underlined a particularly common phenomenon, i.e. the frequency in which an excess of contemplation hinders us from acting adequately:

But what of the second question: why does Aristotle think that we can contemplate our friend's actions better than our own? His idea, I suggest, is that too much selfconsciousness about the performance of an activity undermines its chances of

15 "[...] for what is is the use of such prosperity without the opportunity of beneficence, which is excersiced chiefly and in its most laudable form towards friends (gignetai malista kai epainetotate pros filon)?" (Nicomachean Ethics, 1155a8). The presence of friends is essential for Aristotle in a fulfilled life. Even if we had the greatest number of goods humanly imaginable, our existence would be miserable if we could not share them with our friends. Among the goods of which Aristotle speaks here one would have to count magnificent and splendid actions. Of course, to be object of similar action can be a stimulus for us to emulate our friends in virtue of our similar dispositions. 
success. To exercise one's skills in the solution of a practical problem, one must focus on the problem itself, and not reflect on those skills. The musician, for example, must think about the notes to be played, and not about his virtues as a musician. Similarly, the courageous person thinks about how to win this particular battle, and is too engaged in this activity to step back and enjoy the observation of a courageous man in action. The political leader justly resolving a conflict between other citizens must be thinking about the details of their dispute, whereas an admiring friend can observe his skills as a negotiator. ${ }^{16}$

In fact, when we perform a deed we do not reflect on the nature of our ethical qualities and we cannot properly contemplate our virtues. What happens is that we become virtuous while performing ethical deeds, and in a second instance, we are capable of evaluating the dimensions of our actions from a wider perspective. To reflect on such things in the moment of our performance, as Kraut says, would hinder us from acting competently in complex situations. Without question, this subject is closely related with the Aristotelian idea of 'practical truth'. While in some disciplines or sciences we obtain a truth of an intellectual nature, the truth we look for in ethics is of the kind that will draw us closer to happiness. ${ }^{17}$ In exact sciences like mathematics there is a high degree of certitude of reaching a correct result if we follow a certain procedure. In the case of human action, according to Aristotle, we are not provided with the same advantages, given the fact that we do not have a univocal method by means of which, in every case and circumstance, we can perform virtuous deeds. In other words, it is not easy to deliberate a priori which of our choices are good. We only realize that our decisions are good once the action that followed them is performed and we take certain distance to judge it retrospectively. In the moment of acting it is often impossible to analyze exhaustively the scenarios to which our choices could lead us. If we evaluated from a theoretical stance all our possibilities we would never act and, consequently, we would not be able to perform virtuous deeds. We ponder our motivations and the direct impact that our actions had or could have had on other individuals: that is why we have always to consider the assertive dimension of practical truth.

The 'productive' nature of human actions places us in condition in which we look backwards to the things we have done, and as virtuous individuals we do this with the aid of our friends. At first glance it seems easier that we gain awareness of the real magnitude of our endeavors by submitting the 
evaluation of our actions to the judgment of others who hold us in great esteem. As a sharer of the same set of virtues and values, our friend is a trustworthy agent with whom we can review our previously performed actions. The selfknowledge that goes in hand with this interaction, however, does not pertain only to our condition as ethical agents. Its benefits seem to extend even beyond the present, because we can act better in future instances if we make of this reflective exercise our habit.

Kraut's explanation is highly suggestive, for it stresses the complexity of human action and the multifaceted variety of approaches by which an individual can judge, perform, and perfect his deeds. It is curious, however, that Anthony Kenny adduces almost the opposite reasons to justify the need of friends for self-knowledge. According to Kraut, the need of friends is crucial since there is always the possibility that we incur in an excess of contemplation while performing an action. Hence we need to trust the judgment of our actions to our friends, even if it is for a very short period of time. In contrast, Kenny's argument is that our incapacity to remain always in a contemplative state makes us need friends. ${ }^{18}$ While Kraut's interpretation seems to be directly linked with the concept of the Aristotelian practical truth, Kenny's reading seems to be more close to the X book of the Nicomachean Ethics and even to some passages of the Metaphyisics. If the most 'divine' activity' man can perform is contemplation, it follows from this that the interruption of such activity would carry disgraceful consequences on the individual in question. Kenny holds that the peril our friends prevent us from is not, as Kraut supposes, an excess of contemplation. The danger we run is rather to abandon, even momentarily, such a state. Under these assumptions, friends would seem to be some kind of consciousness similar as ours, towards which we could recur when the contingencies of life force us to suspend our contemplative activity.

This interpretation does not ignore naively the passages of the Nicomachean Ethics in which Aristotle says that friends are essential to happiness. It would be absurd to consider friends only as rational creatures that help us perfect our knowledge. As Kenny remarks, Aristotle himself notices this problem and

18 "Presumably Aristotle means that reflection on our own activity is likely to have a disruptive effect on the activity itself. If so, then it is not so much our self-consciousness as the imperfection of our mode of self-consciousness which makes the need for friends so crucial in human life" (Anthony Kenny, Op. cit., p. 46-47). The argument of Gauthier and Jolie he quotes is also of great interest: "Si nous avons besoin d'amis, ce n'est pas parce que nous possédons la conscience, c'est parce que nous ne la possédons que dans un état imparfait, voilà ce que montrait le premier argument (1169b30-1170a4): nous sentons mieux le bien d'autrui que le notre propre, et donc nous en éprouvons plus de joie, fût-il moindre. Voilà un des fondements de notre besoin d'amitié et une des raisons pour lesquelles Dieu, lui, n'a pas besoin d'amis: il posséde la conscience à l'état parfait, ou plutôt, il est conscience pure (Met, 1074b33-1075a5)" (Ibidem). 
makes great emphasis on our need of friends. But still, Kenny's interpretation seems to privilege excessively contemplative happiness over political life. It is perfectly clear what he and Gauthier-Jolie believe: God does not need friends because of the mere fact that his activity is energeia, that is to say, his existence is in itself perfect, as well as the pleasantness attached to it. Friends, in contrast, cannot enjoy themselves in the same way. Human life is indissolubly united to praxis and thus we have to endure a lot of hardships in order to remain in such a state. While God's intellectual life is complete and self-sufficient, human consciousness is imperfect and needs to be complemented by the activity of others.

Instead of pleading for the superiority of a reading over the other, I would like to remark that both make emphasis on different aspects of friendship. One must complement each of these interpretations in order to understand friendship's role in moral self-knowledge. To be sure, Kraut's analysis about the excess of contemplation in view of the performance of concrete actions is of great phenomenological relevance, but by no means is the only way in which friends play a role on self-knowledge and moral development. A friend is another self, as we mentioned before, who shares our orientation towards good and chooses similar means as ours to achieve his goals. If we only took Kraut's analysis as a point of reference, we could not explain why we enjoy contemplating a friend performing virtuous deeds and, more importantly, why this has concrete repercussions on our idea of virtue and good.

Analogously, Kenny's reading underlines a very interesting phenomenon, i.e. the effect of friends on our own moral or affective state. Nevertheless, his extreme dependence on the idea of happiness in book X makes it very difficult to explain the optimal development of our capacities by the aid of friends. To put it simply, if we follow his line of argument to its last consequences, it would seem that friends are only instruments we use to remedy our own imperfect condition as contemplative agents. It is clear to me that this is not Kenny's intention at all, but the specific weight he lays on this criterion could easily lead to that conclusion.

In general terms, not only these readings, but any interpretation that provides a univocal solution to the question of why we are more conscious of the actions of our friends than ours seems to leave many elements aside. As can be seen from the above discussion, Aristotle himself did not answer this question systematically, but his acute analysis of virtuous friendship allows approaches to the subject from a wide variety of legitimate perspectives. These different paths examined, in consonance with the exigency of reasonable rigor 
formulated in book $\mathrm{I},{ }^{19}$ are not to be thought of as infallible. In my opinion, no method in practical matters is completely infallible. In ethics, particularly, the possibility of self-deceit always remains open. It follows from this we cannot demand from our friends unreasonable things. Friendship is a virtue in which certain mutuality of knowledge is achieved, but that knowledge is neither definitive nor perfect. 